\title{
INSURGÊNCIA, PLANEJAMENTO E A PERSPECTIVA DE UM URBANISMO HUMANO ${ }^{1}$

\author{
INSURGENCY, PLANNING AND THE PROSPECT \\ OF A HUMANE URBANISM
}

\author{
Faranak Miraftab \\ University of Illinois at Urbana-Champaign, Departament of Urban + Regional Planning, Urbana-Champaign, Illinois, Estados Unidos da América
}

Obrigada por esta apresentação. Inicialmente, gostaria de agradecer à comissão organizadora do World Planning Schools Conference por me convidar para abrir esse importante diálogo entre colegas de todo o mundo. É uma verdadeira honra e um privilégio me dirigir a um grupo internacional de estudiosos de renome, sendo que com alguns dos quais continuo a aprender. Como sempre, o conhecimento é uma produção coletiva, e, portanto, o que compartilharei com vocês hoje são meus conhecimentos, adquiridos através do diálogo com ativistas e acadêmicos de várias partes do mundo.

Não preciso dizer a esta audiência que vivemos em um momento de crise, uma crise global que não é apenas uma crise do capitalismo, mas também do planejamento como uma profissão e como uma ideia. Por isso, a urgência de nossas conversaçôes neste congresso mundial, para discutir como podemos repensar o planejamento, o qual é parte integrante da crise contemporânea, e imaginar práticas de descolonização que tornem possível um urbanismo humano. A crise contemporânea é insidiosa e infecta todas as dimensóes da vida, em todos os cantos do globo. Mas isso não significa que estamos todos nela da mesma forma; essas crises afetam as pessoas distintamente em diferentes lugares, de formas que são injustas e desiguais. Poderosas economias, que produzem a desumanidade das crises globais, entretanto raramente assumem a responsabilidade por sua criação.

A atual guerra no Oriente Médio e seu deslocamento global é um exemplo.

Hoje, mais de 60 milhóes de pessoas, ou seja, uma em cada 122 pessoas no mundo, foram expulsas de seus lares pela guerra e outros perigos, uma taxa de sofrimento pior do que em qualquer outro momento da história humana. Mas, enquanto o mundo tem os seus olhos em quase um milhão de fugitivos que enfrentaram o Mar Mediterrâneo para alcançar a Europa, apenas cerca de 300.000 receberam a assim chamada "hospitalidade europeia". A grande maioria dos refugiados permanece próxima a seus lares, sem muita atenção global, em lugares como a Turquia, Jordânia, Líbano, Iraque, Irã e Egito, em campos de refugiados como Zaatari na Jordânia, os quais são agora uma característica permanente das cidades e uma forma de urbanização.

Essa é, de fato, a era do desterro global, seja por causa das guerras e do petróleo, seja por causa da ganância do capital imobiliário gerando espoliação e expulsão urbanas.

Enquanto Congresso Mundial das Escolas de Planejamento (WPSC - 2016, World Planning Schools Congress), os debates em que embarcamos nos próximos dias concernem a como nós, enquanto acadêmicos do planejamento, treinando as próximas geraçôes de profissionais de planejamento, respondemos e nos engajamos em relação a essas crises e injustiça.

Eu argumento que o planejamento está se defrontando com sua própria crise de identidade e legitimidade, uma crise que emerge de sua esquizofrenia profissional, razão pelo que sua própria imagem e ideia da profissão não se encaixam. Daí, portanto, a necessidade de um novo tipo de planejamento, de um novo significado e de uma nova imaginação. O planejamento progressista necessita romper com os Limonad, docente do Programa de Pós-Graduação em Geografia da Universidade Federal Fluminense (POSGEO/UFF). 
postulados que o conduziram a tal crise existencial. Necessita de uma virada ontológica na teorização das práticas de planejamento. Alguns a designam de planejamento insurgente, outros, inclusive alguns de nossos colegas aqui no Rio de Janeiro, a chamam de planejamento conflitivo.

Figura 1: Campo de Refugiados Zaatari, Jordânia, 80.000 pessoas

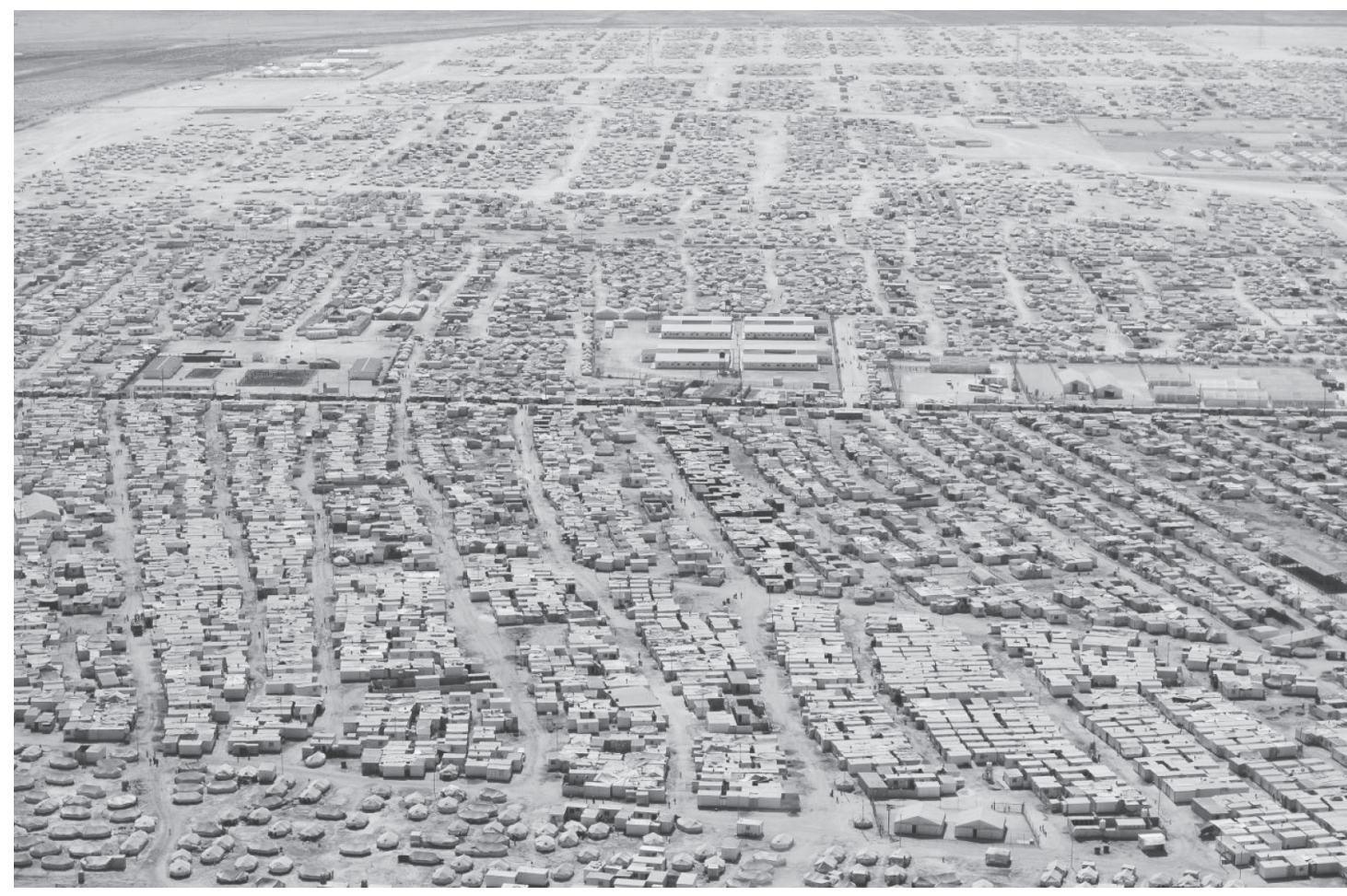

Disponível em: <https://www.foreignaffairs.com/articles/levant/2015-10-20/help-refugees-help-themselves>. Acesso em: 15 set. 2016.

Nesta apresentação enfoco como tal ruptura ontológica na teorização das práticas de planejamento requer, em primeiro lugar, reconhecer o leque de práticas além das sancionadas pelo Estado e poderes corporativos - nomeadamente as práticas insurgentes; e em segundo lugar, requer descolonizar a imaginação e as possibilidades para o futuro. Para isso, precisamos recorrer às práticas subordinadas, amadurecidas em movimentos anticoloniais e anticapitalistas de longa duração. Aí encontraremos a inspiração, os valores e os princípios orientadores para práticas que podem promover um futuro e um urbanismo mais humanos.

Deixem-me desenvolver essa argumentação passo a passo. Eu o faço em três atos:

Ato I. entendendo a esquizofrenia do planejamento;

Ato II. práticas insurgentes como um tipo diferente de planejamento;

Ato III. imaginação e a urgência em descolonizar o futuro.

E, então, finalizarei com uma breve reflexão sobre o que tudo isso representa para o ensino de planejamento. 


\section{ATO I: A ESQUIZOFRENIA DO PLANEJAMENTO}

O planejamento enquanto uma profissão, se auto enaltece por atender ao bem público, mas os planejadores profissionais frequentemente encontram-se a serviço do bem privado.

* Essa esquizofrenia do planejamento é posta a nu quando:

A promoção de conjuntos habitacionais de renda mista em Chicago traduz-se na remoção dos habitantes pobres e racialmente discriminados de conjuntos habitacionais públicos (Figuras 2 e 3).

Em Chicago, conforme se elevaram os preços dos imóveis e a localização dos conjuntos habitacionais públicos tornou-se financeiramente atrativa, os conjuntos públicos foram demolidos em nome do desenvolvimento de comunidades de renda mista. O resultado do planejamento para as habitaçôes integradas foi a expulsão por gentrificação - por exemplo, o aluguel de novos apartamentos de dois quartos ${ }^{2}$ na área está acima de US\$3.000.

Figura 2: Demolição do Conjunto Cabrini Green, Chicago

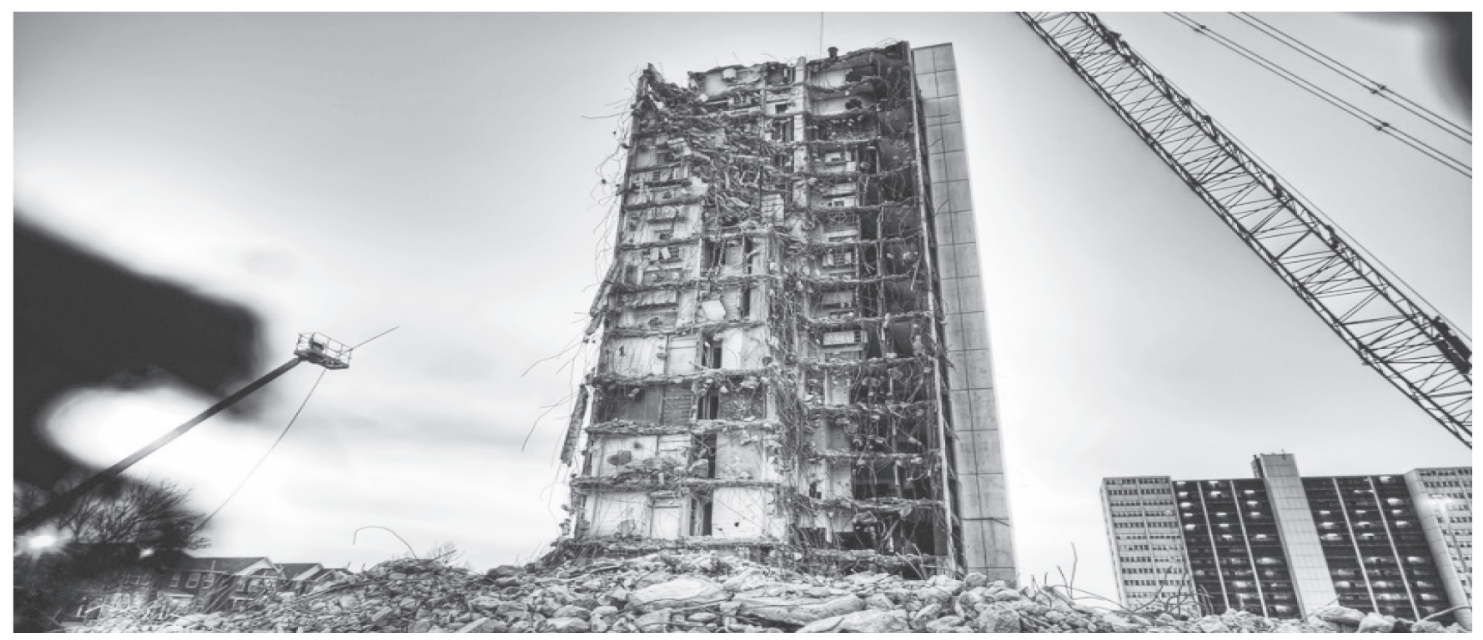

Disponível em: <http://inthesetimes.com/article/18606/70-acres-cabrini-green-documentary-chicago-housing-authority>. Acesso em: 15 set. 2016.

Figura 3: Cabrini-Green - Projeto Habitacional de Renda Mista

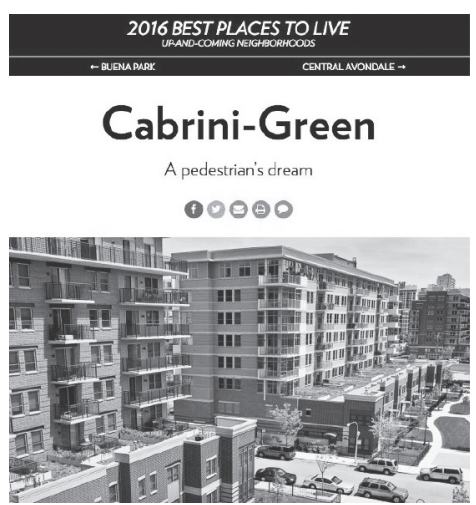

Disponível em: <http://www.chicagomag.com/Chicago-Magazine/April-2016/chicago-neighborhoods/CabriniGreen/>. Acesso em: 15 set. 2016.

2 Disponível em: <http://picturethehomeless.org/wp-content/uploads/2015/12/Homeless_People_Count2.pdf>. Acesso em: 15 jun. 2016. 
* Esta esquizofrenia do planejamento é posta a nu quando:

Transportes eficientes em Mumbai se traduzem em espoliação e expulsão.

O projeto da autoestrada costeira em Mumbai promete uma combinaçáo de 33,20 km de "pontes sobre o mar, vias elevadas, solo recuperado e túneis submarinos"3 para atravessar a baía, reduzir os engarrafamentos de tráfego e os níveis de poluição de Mumbai. Os planejadores também prometem significativos embelezamentos e paisagismo ambiental que irão aumentar a qualidade de vida.

Mas o Tribunal do Povo Independente, trabalhando com o Coletivo de Mumbai por Alternativas Espaciais ${ }^{4}$, mostra que "a autoestrada atenderá apenas a pouco mais de $1 \%$ da população de Mumbai" - aqueles que dirigem carros e viajam diariamente na parte mais desenvolvida da costa Oeste da cidade. Pior ainda, o projeto destruirá a ecologia costeira e o sustento de comunidades costeiras de pescadores cujas vidas dependem da orla costeira.

Embora o planejamento de transportes justifique e promova um megaprojeto em nome do bem comum, ultimamente, nós o vemos servindo a promotores e ao capital imobiliário.

* Essa esquizofrenia do planejamento é posta a nu quando:

Em Cape Town - África do Sul, o planejamento empresarial se traduz na transferência do custo de revitalização econômica para os ombros dos municípios pobres. Enquanto essa revitalização urbana da Melhoria dos Bairros da Cidade (City Improvement Districts, CID), trouxe "I love my laundry cafe" (Figura 4) para a vizinhança do centro, onde Érica pode desfrutar de seu vinho, café e Internet durante a lavagem de suas roupas; para Nomvisiswano nunca se cumpriu a promessa constitucional de seu direito a serviços básicos. Lavar roupas é uma batalha diária, em uma das poucas torneiras comunais na periferia do assentamento de Marikana, em Phillippi (Figura 5).

Quando concordaram com a criação da Melhoria dos Bairros da Cidade (CIDs), há mais de uma década, os planejadores profissionais prometeram que as melhorias dos bairros revitalizados seriam boas para todos. Mas não foi assim para Nomvisiswano e para milhóes de outros.

De fato, o problema é muito pior do que isso. Falta de água e de saneamento também estão conectadas, de formas assustadoras, com a violência de gênero.

Veja-se o caso das duas irmãs adolescentes do estado de Bihar, na Índia, as quais, em uma tarde de maio de 2012, saíram de seu barraco para defecar do lado de fora, longe de todos, onde não seriam vistas e teriam privacidade. Mas, elas nunca voltaram. Seus corpos mortos e violentados foram encontrados, mais tarde, dependurados em uma mangueira.

Se as mulheres tivessem acesso seguro a sanitários, apenas em Bihar, cerca de 400 estupros teriam sido evitados naquele mesmo ano, relata o chefe de polícia de Bihar. ${ }^{5}$

É claro que esse assunto afeta pessoas bem além das fronteiras de Bihar.

Mas como a profissão de planejamento serviu ao bem público em um caso tão grave de injustiça espacial? Meninas e mulheres não são suficientes como um "público"? E sua segurança e suas vidas não são suficientes para um "bem"?

A questáo de fundo é que o Estado capitalista e os especialistas que buscam manter o status quo através da inclusão democrática liberal defrontam-se com as limitaçôes de sua promessa.

O planejamento como o conhecemos está-se defrontando com uma crise de legitimidade.

Suas contradiçóes e falsas promessas manifestam-se em crescentes desigualdades. E as injustiças espaciais que propicia são a evidência patente de "um imperador sem roupas".

3 Disponível em <https://csaweb.org/2015/10/09/mumbais-coastal-road-social-environmental-impacts/> Acesso em 15 de jun. 2016. 4 Disponível em: <https://csaweb.org/2015/10/09/mumbais-coastal-road-social-environmental-impacts/>. Acesso em: 15 jun. 2016. 5 Disponível em: <http://www.bbc.com/news/world-asia-india-22460871>. Acesso em: 15 jun. 2016. 
Figura 4: Loja da rede I love my laundry, Cape Town, África do Sul

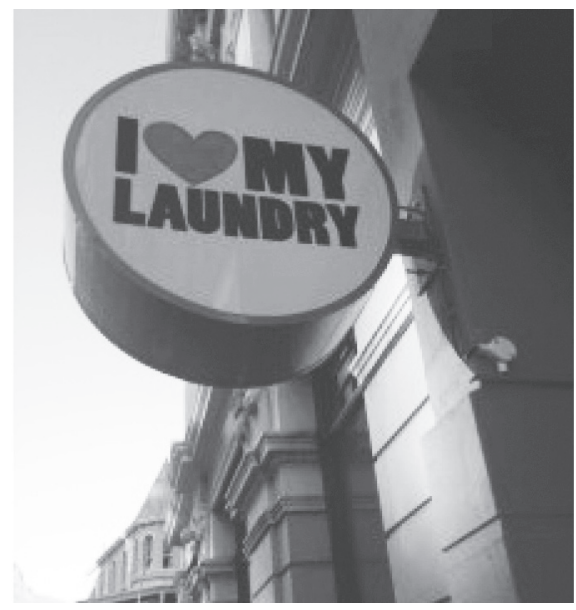

Disponível em: <http://showme.co.za/capetown/news/i-love-my-laundry-in-buitenkant-street-opening-night/>. Acesso em: 15 jun. 2016.
Figura 5: Nomvisiswano lavando sua roupa na periferia do assentamento de Marikana, em Phillipi

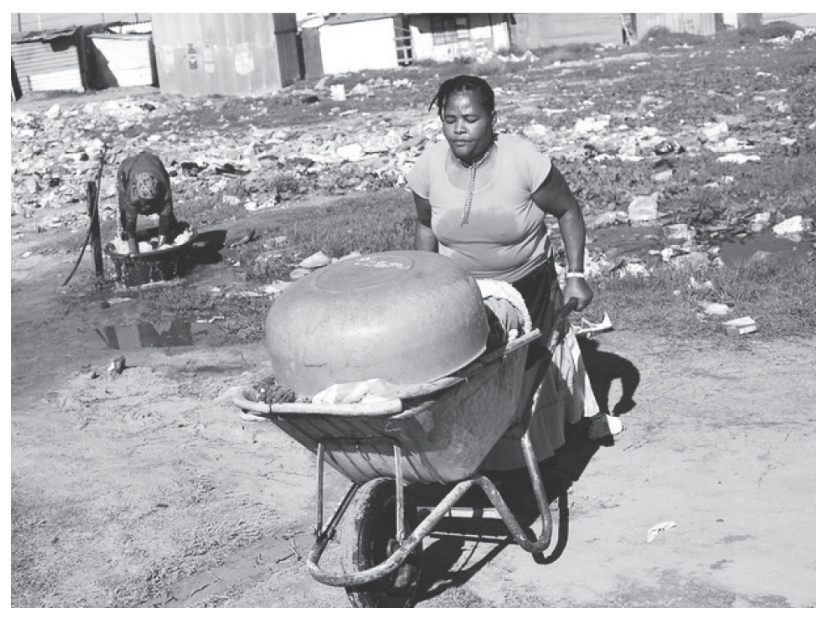

Disponível em: <http://www.groundup.org.za/article/marikana-residents-struggle-water/ please everywhere change Bongani to Nomvisiswano>. Acesso em: 15 jun. 2016.

- Necessitamos de um tipo diferente de planejamento.

- De fato não só o necessitamos, mas um tipo diferente de planejamento é possível.

- Onde podemos ver isso?

Cidadãos, ao redor do mundo, tomaram suas cidades em suas próprias mãos - de Gezi Park, em Istambul, à zona Sul de Chicago, aos piqueteiros, em Buenos Aires, e dizem "basta! Nós já tivemos o suficiente! Que se vão todos!”

Necessitamos considerar essas práticas seriamente e reconhecê-las como instâncias do fazer a cidade, como exemplos das pessoas planejando seus próprios futuros, um futuro que corporifica um urbanismo humano - algo que a profissão de planejador como a conhecemos falhou em fazer.

Para discutir essas experiências como novas práticas de planejamento, necessitamos de uma nova imaginação, um novo léxico, um novo repertório de práticas e um distinto entendimento de justiça.

O planejamento insurgente pode ser a estrutura que pavimenta a estrada rumo a um urbanismo humano.

- Todavia, como é esse planejamento insurgente? Com que se parece?

- Como reconhecê-lo, ao vê-lo?

- Quais são seus princípios condutores, valores, ideais, imaginaçôes, e como procede a uma ruptura fundamental com o planejamento como o conhecemos?

Essas são questôes que abordo no Ato II.

\section{ATO II: PRÁTICAS INSURGENTES}

O planejamento insurgente é um planejamento alternativo à medida em que tem lugar entre comunidades subordinadas, sejam assentamentos informais e municípios em ex-colônias ou comunidades desfavorecidas no estômago da besta - a América do Norte e a Europa Ocidental.

Neste estágio histórico particular do neoliberalismo onde a inclusão é um álibi para a exclusão e normalização da dominação neocolonial, a falência do planejamento inclusivo liberal nos pressiona a repensar os parâmetros epistemológicos e ontológicos das teorizaçôes e práticas de planejamento. Nós 
somos pressionados a re-centralizar a política da justiça na teorizaçáo do planejamento e romper com as filosofias políticas que o guiaram durante boa parte do século XX. O planejamento insurgente, eu considero, persegue tal ruptura ontológica e epistemológica em nossa conjuntura neoliberal contemporânea.

O planejamento insurgente provêm de uma tradição radical anterior na teoria de planejamento, formulada inicialmente por Friedmann (2011) no final dos anos 1980, depois desenvolvida por Sandercock (1998), Beard (2002) e outros autores, que clamaram pelo reconhecimento das práticas cidadãs como formas de planejamento.

O planejamento insurgente avança essa tradição ao abrir a teorização do planejamento a outras formas de ação, para incluir não apenas formas selecionadas de ação dos cidadãos e de suas organizaçóes sancionadas pelos grupos dominantes, as quais designo de espaços de ação convidados; mas também as insurreiçôes e insurgências que o Estado e as corporaçôes sistematicamente buscam colocar no ostracismo e criminalizar - que designo de espaços de ação inventados.

Isto, eu argumento, não é apenas epistemológico (inclusão de comunidades locais e de voz e conhecimento local) mas também ontológico.

Ativistas insurgentes póem em prática uma distinta compreensão de justiça. Para alcançar um resultado, eles mudam a base do seu clamor por justiça, da concepção de justiça de Rawls (1971) enquanto igualdade para a noçáo de Young (1990), da justiça baseada no reconhecimento da diferença e de sua política. Eles entendem não ser suficiente dar direitos individuais e um tratamento igualitário como advoga a filosofia política liberal da justiça. Ao contrário, pedem o urgente reconhecimento de formas de opressão autodeterminadas e baseadas em grupos.

Tal compreensão da justiça faz o debate da inclusão passar da representação para a autodeterminação - uma mudança na perspectiva que valida a ação direta coletiva de cidadãos e que volta-se da democracia representativa para a democracia participativa. $\mathrm{Na}$ democracia representativa, os cidadãos delegam seus direitos a outros - representantes políticos, burocratas ou especialistas técnicos - para atuar em seu melhor interesse. Em contraste, na democracia participativa os cidadãos reconhecem a inadequação dos direitos formais e não incumbem a outros advogar por seus interesses mas, ao contrário, tomam parte diretamente e formulam decisóes que afetam suas vidas. A democracia participativa consequentemente promove uma forma de cidadania que é multi-centrada e que tem múltiplas atividades, incluindo os cidadãos e suas ações sociais diretas.

Isso tem importantes implicaçóes para o planejamento. Porque rompe ontologicamente com a noção liberal de inclusão, que guiou o planejamento profissional durante a maior parte do século XX. Práticas insurgentes perfazem uma ruptura ontológica não por almejarem uma fatia maior da torta, mas por desejarem um outro tipo de torta - uma torta ontologicamente distinta. As práticas insurgentes e o planejamento insurgente não buscam por inclusão através de uma melhor representação (seja de especialistas ou de políticos); mas buscam a inclusão autodeterminada, na qual os direitos das pessoas são reais e praticados.

Conforme o planejamento insurgente descentraliza o papel da representação e dá atenção à ação direta e aos meios de inclusão, ele muda também o sujeito de sua teorização - do planejador para o planejamento. $\mathrm{Na}$ arquitetura conceitual do planejamento insurgente, planejadores profissionais nada mais são que um ator em um conjunto de atores que conformam o questionável campo de ação conhecido como planejamento. A preocupação principal é portanto com as práticas e não com seus atores.

À medida que os espaços de ação convidados e inventados dos cidadãos são críticos para a minha abordagem do planejamento insurgente, tomarei uns poucos momentos para esclarecer o conceito.

Os dois tipos de espaços que discuto encontram-se em uma relação dialética e de interação mutuamente constituída, não em uma relação binária. Evidências concretas mostram que as práticas dos movimentos sociais, que almejam alcançar mais do que as necessidades individuais, que é a meta da 
inclusão liberal, frequentemente tem de se mover através e entre aqueles espaços de acordo com as necessidades específicas da luta. Mas instituições de poder, tais como a mídia dominante, o Estado, organizaçôes internacionais de ajuda, configuram esses espaços convidados e inventados em uma relação binária, e tendem a criminalizar os últimos, designando apenas os primeiros como espaços "apropriados" para as vozes e participação dos cidadãos.

Devemos observar que uma construção binária de espaços convidados e inventados arrisca uma concepção fixa equivocada de estabilidade em cada espaço. Essa construção binária desconsidera a flexibilidade e a natureza inovadora do capitalismo e como ele se desdobra sobre o que quer que esteja a sua margem e busca incorporar o que quer que possa constituir uma ameaça a ele. O que hoje é uma alternativa pode se tornar uma tendência dominante e despolitizada pela repressão e cooptação amanhã, com sua força transformadora minada - deixando os ativistas com um "telefone de brinquedo sem sinal para chegar a lugar nenhum" - metáfora que meu colega Ken Salo usa para esses movimentos roubados.

Movimentos radicais necessitam, assim, reinventar constantemente seus espaços de ação através de "práticas de ruptura e criaçáo". Porque, conforme Marcelo Svirsky (2010), o ativismo que "trilha caminhos de conflito reconhecidos está sempre em risco de ser sitiado e contido pelo organismo de Estado", e da conformidade à cumplicidade é um curto passo, como adverte Buchanan (2000). O ativismo que busca apenas garantir os mecanismos da democracia representativa constitui o que Svirsky (2010) designa de "ativismo escravo".

Este tipo de ativismo escravo é o que a teoria despolitizada de planejamento celebrou e popularizou como planejamento inclusivo através da participação cidadã, do desenvolvimento comunitário de movimentos sociais e envolvimento de movimentos sociais. O planejamento insurgente rompe com esse modo de pensar de formas radicais. O planejamento insurgente desafia o confinamento e a conformação das açóes dos cidadãos às normas do Estado democrático liberal e do aparato de mercado e também reconhece como os cidadãos podem usar essas normas para induzir uma ruptura e criar algo novo.

Os cépticos, todavia, levantam importantes questóes:

- Como reconhecemos práticas insurgentes que contribuam para construir uma democracia participativa e para criar as bases para se desenvolver um urbanismo humano?

- Será que todo ato de insurreição ou disruptivo constitui uma contribuição progressista a um urbanismo humano? Ou pode ser antidemocrático, reacionário ou mesmo fascista?

Tome-se, por exemplo, o caso Clive Bundy (Figura 6), nos Estados Unidos, um movimento da direita que envolveu, durante quase seis semanas, uma ocupação e um confronto armado com as autoridades de Nevada em relação aos direitos de pastagem do gado em uma área de preservação da vida selvagem. Os insurgentes Clive Bundy e seus filhos, com o apoio de outros vaqueiros resistiram à imposição de taxação federal. 
Figura 6: Mobilização armada de direita, liderada por Clive Bundy, em Nevada, Estados Unidos

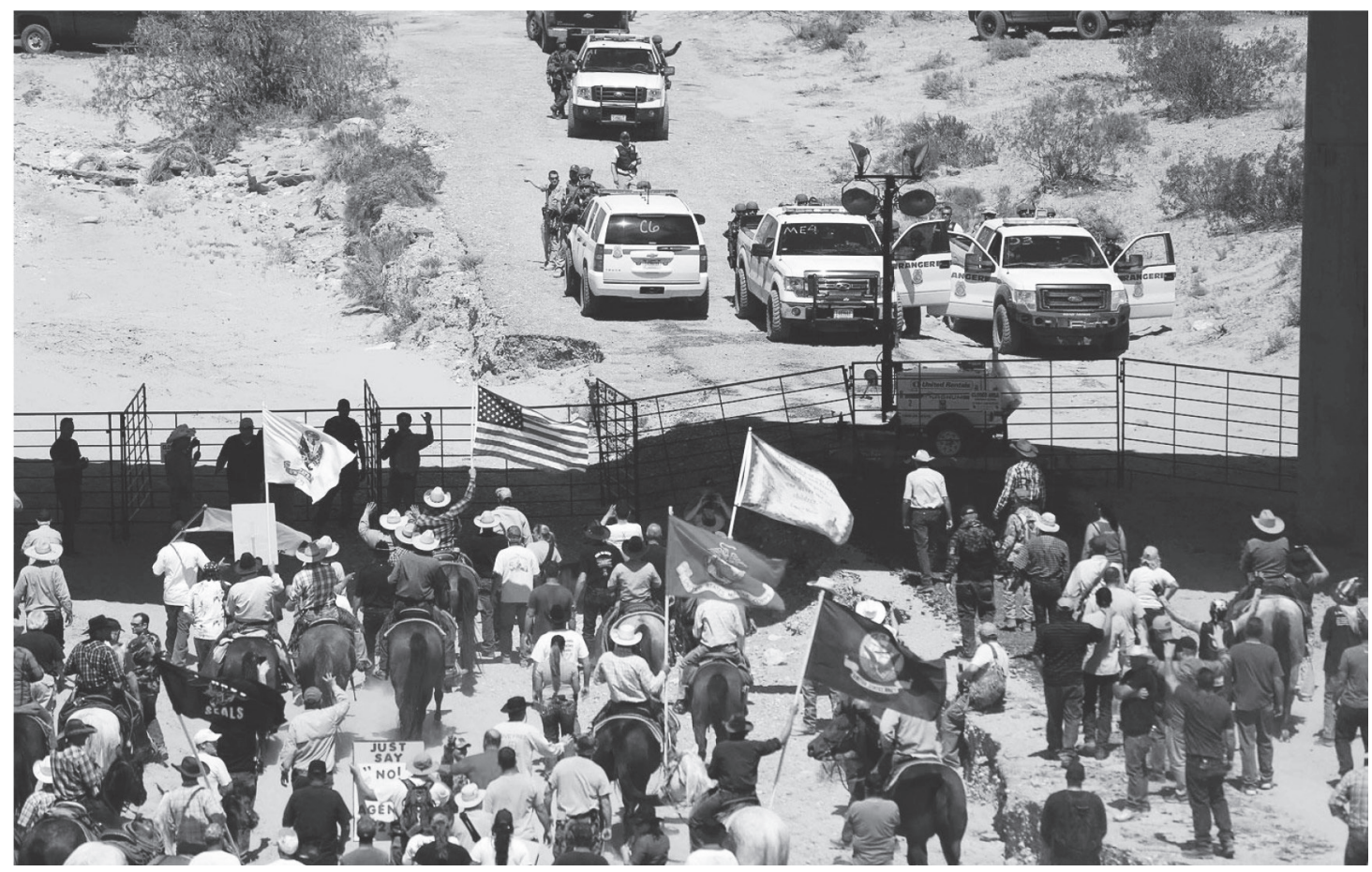

Fonte: Steve Marcus/Reuters/Corbis.

Ou consideremos os frequentes distúrbios xenofóbicos na África do Sul, inclusive o de 2015, no cabo Ocidental, onde tive o infortúnio de testemunhar os depoimentos, de partir o coração, de suas vitimas entre os pobres migrantes e refugiados africanos.

Entendo as práticas de planejamento insurgentes ${ }^{6}$, com potencial transformador para um urbanismo humano, em termos de três princípios:

- Transgressão no tempo, lugar e ação: elas transgridem falsas dicotomias entre espaços convidados e inventados do ativismo; elas transgridem fronteiras nacionais ao construir solidariedades transnacionais e movem-se além dos laços do tempo através de uma consciência historicizada.

- Contra e anti-hegemonia: as práticas de planejamento insurgente são anti- e contra-hegemônicas. Elas desestabilizam relações de dominação e são especificamente anticapitalistas.

- Imaginação: práticas de planejamento insurgente são imaginativas. Elas recuperam o idealismo por uma sociedade justa.

Alguns exemplos podem ajudar.

Começo com um breve exemplo de um projeto em curso intitulado "Meio-Oeste Insurgente: Diálogos Transnacionais para um Urbanismo Humano" ("Insurgent Midwest: Transnational Dialogues for Humane Urbanism"), em que estou envolvida com um coletivo de acadêmicos e ativistas em Illinois.

Um dos grupos envolvidos nesse projeto é o Centro Autônomo de Albany Park - Rede Mexicana de Solidariedade (Albany Park Autonomous Center - Mexican Solidarity Network (MSN)), organização de base comunitária com sede em Albany Park, um bairro de Chicago com um grande contingente de imigrantes e latinos, mas associada e articulada em rede com movimentos no México. Trabalha estreitamente com os Zapatistas, com comunidades indígenas e camponesas, com frentes de trabalho em Chiapas, Ciudad Juárez, Guerrero, Oaxaca, Cidade do México no México. 
Suas parcerias estratégicas mais importantes no México são com a Frente Popular Francisco Villa Independiente, organização comunitária com uma base de 100.000 membros na Cidade do México, e com o Consejo Nacional Urbano y Campesino, organização comunitária com base urbana e rural de 30.000 membros em Tlaxcala.

A MSN adota práticas transgressoras não apenas por seu alcance e intercâmbio transnacional, mas também por se mover além e através de "espaços convidados e inventados" de ativismo. Em anos recentes, predominantemente grandes sociedades imobiliárias de responsabilidade limitada começaram a adquirir edifícios de apartamentos de aluguel em Albany Park, expulsaram os inquilinos desses edifícios, fizeram algumas melhorias e recolocaram as unidades de volta no topo do mercado imobiliário, a preços inacessíveis aos moradores anteriores - produzindo o que é conhecido como um típico processo de gentrificação.

Para combater esses processos de gentrificação e remoção o Centro Autônomo de Albany Park utiliza instrumentos legais, disponíveis através dos "espaços convidados", para estender os prazos de aluguel e proteger os direitos legais dos inquilinos. Porém, não se limita apenas a tais práticas, também mobiliza através de um leque de "espaços inventados" de ativismo. O que inclui açóes diretas como protestos em frente dos bancos responsáveis pela gentrificação em suas vizinhanças e pela crise hipotecária imobiliária nacional que deixou muitas famílias sem teto (Figura 7).

Figura 7. Protesto pacífico em frente aos bancos para expô-los pelo fato de provocarem penhoras e remoçôes

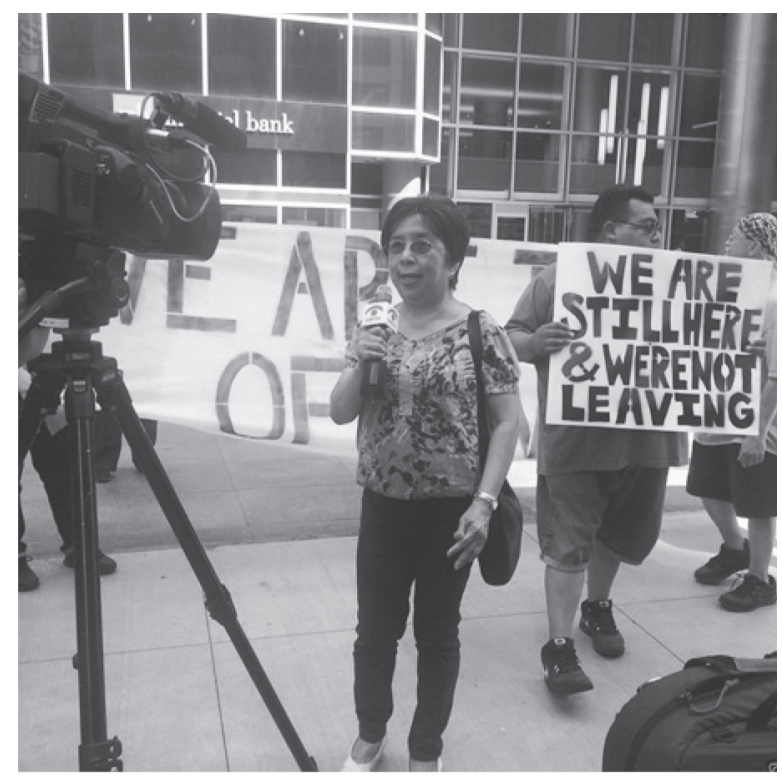

Fonte: Centro Autônomo de Albany Park - MSN.

O Centro Autônomo de Albany Park cria, também, mapas em tempo real da gentrificação, marcando os edifícios que as sociedades imobiliárias adquirem, e organiza os inquilinos nesses edifícios em associaçôes de moradores específicas de cada edifício para sabotar as remoções e/ou a reforma dos edifícios de onde as pessoas são removidas. Suas práticas transgressoras assemelham-se ao uso da estratégia "espada e escudo". O escudo para estender a permanência e proteger os residentes de baixa renda, a espada para acionar açóes públicas contra os proprietários, em particular contra as sociedades imobiliárias que adquirem quantidades crescentes de unidades em bairros em processo de gentrificação como Albany Park.

Outro exemplo pode ser as práticas insurgentes de cidadãos no Gezi Park, em Istambul, Turquia, durante o verão de 2013. 
Recentemente, Deniz Ay e eu publicamos um texto ${ }^{7}$ que documenta o sucesso de espaços inventados de ativismo usando atos performáticos de insurgência para parar a demolição do Gezi Park e da Praça Taksim e sua substituiçáo por um shopping center.

Gezi Park e a Praça Taksim adjacente, para aqueles na audiência não familiarizados com Istambul, é um espaço público chave para os residentes de Istambul. É um grande espaço público, e é o centro comercial e de transporte.

Os promotores multinacionais e o capital imobiliário, entretanto, como parte da agressiva neoliberalização do espaço urbano de Istambul, voltaram-se para a apropriação desse espaço para um uso sofisticado e de elite. Durante os vários estágios do planejamento desse projeto de renovação, cidadãos preocupados e organizaçóes civis exauriram os canais liberais representativos de participação cidadã (os chamados espaços convidados) para expressar sua oposição. Mas como se esperava, estes náo eram mais do que uma maquiagem de fachada para a agressiva agenda do capital arrasar tudo e abrir caminho, figurativa e literalmente. No dia da demolição, entretanto, os cidadãos chegaram e inventaram novos meios para participar e serem ouvidos; alguns espontâneos, outros organizados enfrentaram uma forte repressão militar. Mesmo assim, ocuparam a praça, instalaram seu espaço comunal, imaginaram o espaço público como se fora deles mesmos e resistiram aos avanços do capitalismo.

O que é importante, para mim, nesse exemplo são os aspectos performáticos da luta deles e os espaços de ativismos que inventam - performatividade encenada por aqueles "que não contam", para citar Swyngeduow (2015). Uma série de táticas com base no lugar, que simbólica e performaticamente resiste ao re-desenvolvimento na Praça Taksim, re-inventou a praça e deu-lhe um novo significado através do uso imaginativo de seu espaço público.

Por exemplo, uma forma não ortodoxa de protesto: permanecer parado. Um homem permaneceu parado por oito horas consecutivas na Praça Taksim, defronte ao Centro Cultural Ataturk (AKM), que traz a efigie do tamanho de uma parede de Ataturk, pai da naçáo e de seu moderno estado na Turquia, com as bandeiras nacionais do país de cada lado. $\mathrm{O}$ ato de permanecer parado enquanto defrontava esta figura disparou a memória coletiva dos fundamentos da Turquia moderna, que reverberaram entre muitas pessoas da oposição ao governo nacional.

Enquanto o Homem Parado desnorteou as forças policiais, em como manejar os supostamente passivos protestos de massas "apenas parados", também criou uma presença corporal de pessoas. Essa simples presença de corpos no domínio público, como Judith Butler e Athanasiou (2013) ressaltam, gera uma certa força performática através do "Nós estamos aqui", mensagem que também poderia ser re-lida como "Nós ainda estamos aqui" a despeito dos esforços persistentes de despossessão e opressáo. O protesto do Homem Parado tornou-se um ato inovador de prática cidadá precisamente por causa do contexto histórico, espacial e político no qual teve lugar e deu significado a ele.

A "Mesa na Terra” é outro exemplo de espaços inventados e de ativismo. Um mês de luta marcou o primeiro dia do Ramadan, assim muitos esperavam que isto acabaria inevitavelmente com os protestos no Gezi Park. Ao contrário, as pessoas de Gezi reinventaram o espaço da rua mais popular de Istambul (Istiklal), mesclando os ideais do movimento de Gezi Park com os rituais do Ramadan. As pessoas ocuparam a linha do bonde, que atravessa a avenida Istiklal e criaram a Mesa na Terra, como a designaram, para quebrar o seu jejum, recebendo centenas de pessoas compartilhando sua comida uns com os outros. Este ato inovador de usar o trilho do bonde, no meio da vizinhança mais vibrante da cidade e rodeados por restaurantes de alto luxo, foi chave para afirmar a presença deles, o "nós ainda estamos aqui" afetou mas também evocou a imaginação de um urbanismo humano e de um espaço urbano mais comunal.

7 Ver: Ay e Miraftab (2016). 
Figura 8: "Mesa na Terra", Avenida Istiklal, julho de 2013

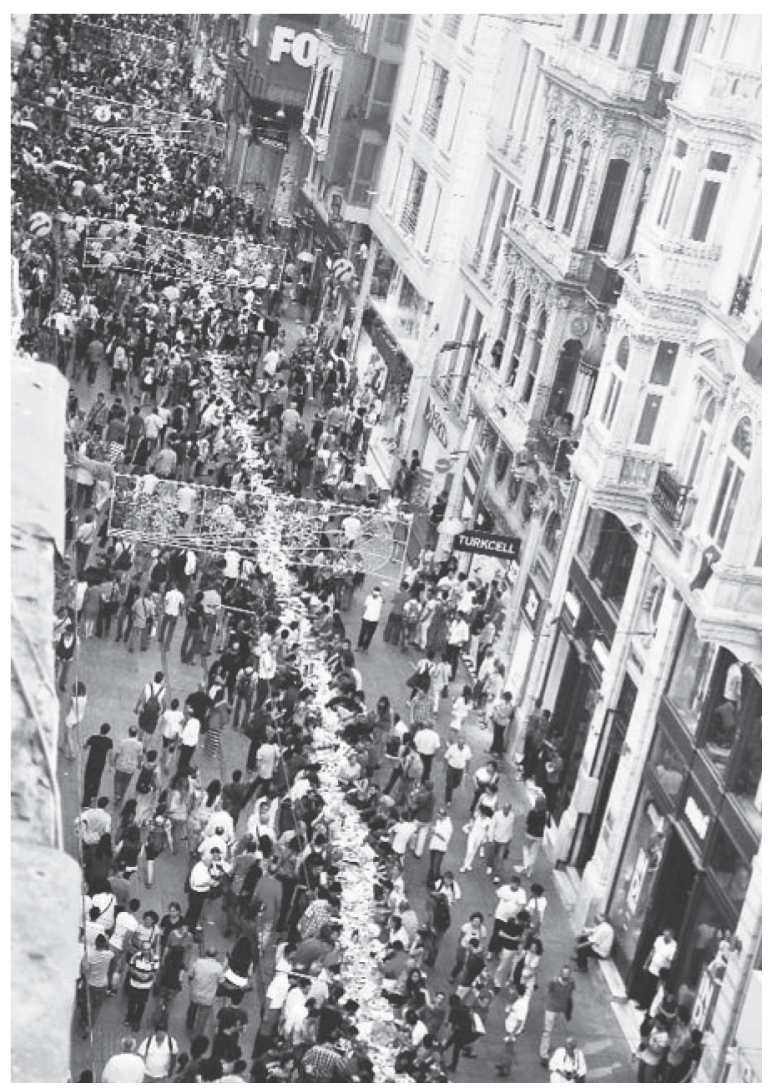

Fonte: Foto de Yagiz Karahan, 2013.

Embora esses movimentos não ofereçam, de forma alguma, um plano urbanístico, suas práticas são fundamentais para obstruir a besta da ganância urbana. Essas práticas podem ou não permanecer válidas para outra luta, outro tempo e lugar, mas necessitamos inventar novas formas de ação, compartilhá-las, criar um repertório, um idioma de planejamento (para usar os termos de Ananya Roy) para empurrar os limites da imaginação e evocar um futuro alternativo que seja pela justiça espacial.

Lutas pela imaginação e descolonização do futuro, enfatizo, são o terreno político chave da luta. Esse é o Ato III, para o qual me volto agora, que tem uma implicação significativa para os educadores de planejamento.

\section{ATO III: IMAGINAÇÃO E A URGÊNCIA EM DESCOLONIZAR O FUTURO}

Os escritos de intelectuais africanos ensinam-nos que a liberação das colônias poderia acontecer apenas através do que Fanon (1986; 1995) designa de "descolonização da mente" e liberação da imaginação. A liberação necessita de uma nova consciência, recuperada da injúria moral colonial, da profunda alienação que acreditava que o desenvolvimento da colônia somente poderia acontecer "sob a condição de rejeitar a si própria” e que importe no atacado cenários e soluções não-africanas (DAVIDSON, 1992).

Afirmo a necessidade de uma nova consciência que libere as imaginações do planejamento. Isso requer descolonizar a imaginação do planejamento questionando suas assumpçóes hegemônicas. 
A luta central com que esta geração se defronta é entre a expansão do domínio da imaginação e o seu encerramento. O futuro é inevitável. É aberto e plural. As pessoas necessitam dele como necessitam do ar, escreve Jan Pieterse (2000). Mas o futuro está também vazio; significando que o que o constitui depende de como é imaginado, suscetível de ser reinventado e "aberto por um horizonte de possibilidades". Por causa de sua abertura e pluralidade, o futuro é um objeto de intensa disputa, segundo Boaventura de Souza Santos (1995).

Mas a abertura sem fim, a pluralidade e imprevisibilidade do futuro também o tornam um território político, um sítio de forte contestação sobre o rumo que pode tomar. Se não ousarmos imaginar o inimaginável, então, o futuro é menos aberto e mais predeterminado como persistência e perpetuação do presente.

A "colonização do futuro" é um conceito de importância chave nessa discussão. Deixem-me elaborar:

Nas primeiras colônias, a terra, os recursos naturais e o trabalho escravo eram objetos da criação de riqueza. Nos anos 1980 Maria Mies e suas colegas, Bennholdt-Thomsen e Von Werlhof (1988), provocativamente, escreveram Mulheres, a Última Colônia. Ou seja, a colonização voltou-se para as mulheres e para a obtenção barata de seu trabalho para criar mais riqueza.

Hoje, entretanto, eu argumento que é o futuro que deve ser invocado como a última colônia - o futuro enquanto um território político, um "território" a ser "ocupado" para salvaguardar seu fechamento por imaginaçôes totalitárias e pela aniquilação de alternativas.

Como um argumento oposto ao do fim da história de Francis Fukuyama (1992), que busca encerrar o futuro, a luta de nossos cidadãos é para superar tal fechamento e abrir o terreno para a imaginação para conceber alternativas. O fim da história como o conhecemos, pode ser também o começo da história como a queremos.

Para isso, algumas pessoas empregam açóes performáticas que evocam a imaginação de um mundo diferente, mesmo que momentânea e temporariamente. Outros, entre os novos movimentos sociais, voltam-se para a ficção científica, para os movimentos de justiça social.

Em resumo, a politização da imaginação e do futuro como um terreno de luta por justiça é chave, se vamos planejar um mundo mais justo, e um urbanismo mais humano. O potencial de insurgência para o urbanismo humano jaz na normalidade que ele interrompe e no novo senso comum que ele ajuda a criar.

\section{E AGORA O ATO FINAL: QUAIS AS IMPLICAÇÕES DESSES DEBATES PARA O ENSINO DE PLANEJAMENTO}

Eu foco em três pontos principais que emergem de inspirações especificas, que compartilhei durante a última hora.

- Primeiro, no núcleo do ensino de planejamento progressista deve haver uma abordagem relacional que promova um curriculum transgressor tanto em conteúdo, quanto em modos de conhecimento;

- Segundo, um ensino de planejamento que mire o futuro necessita preparar os estudantes com linguagens que os conectem a diversos atores, que em contestaçóes modelam o habitat humano;

- Terceiro, como acadêmicos de planejamento devemos usar cada oportunidade para estimular a imaginação e descolonizar o futuro.

Deixem-me explicar:

Primeiro, necessitamos adotar uma abordagem relacional. Uma abordagem relacional no ensino de planejamento expóe as injustiças e desigualdades pela transgressão do tempo, do lugar e das formas de ação.

Para combater uma compreensão paroquial do desenvolvimento, uma abordagem relacional pro- 
move uma compreensão transnacional e historicizada através de todas as áreas do curriculum.

Ela vê o lugar local como poroso, não como um território confinado ou aparte. Vai além do nacionalismo metodológico dos estudos urbanos e do pós-nacionalismo dos estudos globais para expor o custo global do desenvolvimento local.

Um curriculum relacional não ensinaria, portanto, sobre revitalização sem gentrificação; não ensinaria sobre migração sem desterritorialização; não ensinaria sobre o presente sem um agudo sentido de história e não ensinaria sobre o local sem revelar a hierarquia e seu modo de conexão com o mundo. Um ensino relacional de planejamento politiza o curriculum, é politemporal e transnacional, provê os estudantes com analogias e metáforas da exclusão e do elitismo através da inclusão

Segundo, necessitamos preparar os estudantes com variadas linguagens de planejamento que os conectem a atores diversos, os quais contestam e modelam o futuro do habitat humano.

Meu colega Carlos Vainer, da Universidade Federal do Rio de Janeiro, sugere que o planejamento poderia ser entendido como uma linguagem, e o que ele designa de planejamento de conflito oferece uma linguagem técnica e discursiva do planejamento para os movimentos. Isso implica em um ensino de planejamento que prepara os estudantes para se engajarem náo apenas com os espaços convidados, mas também com os espaços inventados de ação cidadã.

O planejamento, entendido como um campo disputado de ação por um conjunto de atores, reconhece os múltiplos centros de poder, meios de ação e linguagens. Os estudantes que nós, como acadêmicos, treinamos podem acabar em organizaçôes sem fins lucrativos da sociedade civil, em autarquias municipais, no mundo corporativo das consultorias ou do setor imobiliário, ou simplesmente como cidadáos preocupados, conduzindo suas próprias lutas por uma experiência de vida humana e um meio de sobrevivência dignos. Nossos estudantes precisam reconhecer o significado de outros atores igualmente importantes no processo de construção da cidade. Eles não podem ser enganados pela criminalização de certas práticas e espaços de ação.

Assim, pode-se perguntar o que devem fazer aqueles que treinamos para obter um emprego como planejadores profissionais? O planejamento insurgente não tem projetos urbanísticos; além de sua estrutura normativa, ele não pode ter um plano urbanístico, um projeto físico, à medida que isso poderia jogar por terra a essência das práticas imaginativas e relacionais que necessita. $\mathrm{O}$ planejamento insurgente é específico do contexto e responde ao conjunto de atores e relaçóes que encontra em um dado contexto disputado. Como cada contexto possui sua própria micropolítica e infrapolítica (para usar o termo de Kelly Robin (1994)), não há uma transmissão genérica de certas açóes a um planejador profissional.

Terceiro, nosso currículo necessita evocar a imaginação para visionar um futuro alternativo - um futuro que incorpore um urbanismo humano.

Para um ensino transformador de planejamento, Fanon ajuda ao mostrar o papel das subjetividades em reforçar ou minar o discurso e a prática da cultura dominante. Fanon escreve sobre a colonização da mente, dos valores e das subjetividades através da falsa promessa de plena cidadania por falar o "francês apropriado". No ensino de planejamento as imaginaçôes dos estudantes são frequentemente sequestradas pelas experiências de planejamento euro-americanas convencionais do mainstream como o "planejamento adequado”. O custo de não usar ideias e ideais convencionais e elitistas de planejamento é que nós não somos ouvidos.

A eliminação de futuros alternativos não se faz sempre através da violência direta, por exemplo, pela criminalização das alternativas. A remoção de práticas alternativas de planejamento pode se fazer também através da violência indireta por meio da depreciação da alternativa - depreciando as práticas. Por exemplo, rotulando-se alternativas como "irreais e que, portanto, não merecem um envolvimento" ou "sem vínculos com a realidade presente" tem frequentemente servido como um meio efetivo para suprimir alternativas.

Nessa era de "realismo", onde os ideais são menosprezados e sonhar é estigmatizado, o exercício da 
imaginação individual ou coletiva de um mundo justo é de valor pedagógico inestimável. Um exemplo nesse sentido é a minha turma de calouros, a quem solicitei, em um pequeno exercício simples de grupo, que imaginassem como uma cidade justa se pareceria ou seria: os estudantes tiveram dificuldades em se envolver com esse imaginário mesmo por cinco minutos. Para educadores de planejamento a fronteira da luta anticolonial e anti-hegemônica é de fato uma luta para descolonizar as mentes e a imaginação dos estudantes, para visionarem as possibilidades de um mundo diferente.

Para encerrar gostaria de enfatizar que, por vivermos em tempos de crise, tanto do capitalismo quanto de nossa profissão de planejamento; estas crises compelem-nos rumo a novas oportunidades. A mais importante oportunidade e desafio ao planejamento progressista para tratar das injustiças espaciais é ousar imaginar - imaginar um futuro radicalmente diferente que seja mais justo e que corporifique um urbanismo humano. Para isso necessitamos também de um repertório de práticas que possam invocar tal imaginaçấo e pavimentar os caminhos para um urbanismo humano. O espaço desse congresso e seu compartilhamento transnacional de ideias e histórias é uma oportunidade única. Espero ansiosa por isso.

Faranak Miraftab é PhD pela University of California, Berkeley, EUA; Docente do Departamento de Planejamento Urbano e Regional na University of Illinois em Urbana-Champaign, EUA.

E-mail:faranak@illinois.edu

\section{REFERÊNCIAS}

AY, D.; MIRAFTAB, F. Invented Spaces of Activism: Gezi Park and Performative Practices of Citizenship. In: GRUGEL, J.; HAMMETT, D. (Ed.). The Handbook of International Development. Londres: Palgrave MacMillan, 2016. p. 555-574.

BEARD, V. A. Covert Planning for Social Transformation in Indonesia. Journal of Planning Education and Research, v. 22, n. 1, p 15-25, set. 2002. https://doi.org/10.1177/0739456x0202200102

BUCHANAN, I. Deleuzism: A metacommentary. Edinburgh: Edinburgh University Press, 2000.

BUTLER, J.; ATHANASIOU, A. Dispossession: the performative in the political. Cambridge: Polity Press, 2013.

DAVIDSON, B. The Black Man's Burden: Africa and the Curse of the Nation-State. New York: Times Books, 1992.

FANON, F. Black Skin, White Mask. London: Pluto Press, 1986.

. The Fact of Blackness. In: ASHCROFT, B.; GRIFFITHS, G.; TIFFIN, H. (Ed.). The Post-Colonial Studies Reader. New York: Routledge, 1995. p. 291-294.

FRIEDMANN, J. Insurgencies: essays in Planning Theory. New York: Routledge. 2011.

FUKUYAMA, F. The End of History and the Last Man. New York: Free Press, 1992.

MIES, M.; BENNHOLDT-THOMSEN, V.; VON WERLHOF, C. Women: The Last Colony. London: Zed Books, 1988.

MIRAFTAB, F. Insurgent Planning: Situating Radical Planning in the Global South. Planning Theory, v. 8, n. 1, p. 32-50, fev. 2009. https://doi.org/10.1177/1473095208099297

; WILLS, S. Insurgency and Spaces of Active Citizenship: The Story of Western Cape Anti-Eviction Campaign in South Africa. Journal of Planning Education and Research, v. 25, n. 2, p. 200-217, dez. 2005. https://doi.org/10.1177/0739456x05282182

PICTURE THE HOMELESS. Homeless people count vacant properties in Manhattan. Nova Iorque: Picture the Homeless, 200[?], Disponível em: <http://picturethehomeless.org/wp-content/uploads/2015/12/ Homeless_People_Count2.pdf>. Acesso em: 25 set. 2016.

PIETERSE, J. N. Global Futures: Shaping Globalization. London: Zed Books, 2000. 
RAWLS, J. A Theory of Justice. Cambridge, MA: Belknap, Harvard University Press, 1971.

ROBIN, K. Race Rebels: Culture, Politics, and the Black Working Class. New York: Free Press, 1994.

SANDERCOCK, L. Framing Insurgent Historiographies for Planning. In: (Ed.). Making the Invisible Visible: A Multicultural Planning History. Berkeley: University of California Press, 1998. p. 1-35.

SANTOS, B. S. Toward a New Common Sense: Law, Science and Politics in the Paradigmatic Transition. London: Routledge, 1995.

SVIRSKY, M. Introduction: Beyond the Royal Science of Politics. In: (Ed.). Deleuze Studies: Special Issue on Deleuze and Political Activism. Edinburgh: Edinburgh University Press, 2010. p. 1-6.

SWYNGEDOUW, E. Urban Insurgencies and the Re-Politicization of the Unequal City. In: MIRAFTAB, F.; WILSON, D.; SALO, k. (Ed.). Cities and Inequalities in a Global and Neoliberal World. New York: Routledge, 2015. p. 173-187.

YOUNG, I. Justice and the Politics of Difference. Princeton: Princeton University Press, 1990. 